\title{
Correcting topographic effect on Landsat-8 images: an evaluation of using different DEMs in Indonesia
}

Deha Agus Umarhadi, Projo Danoedoro

Deha Agus Umarhadi, Projo Danoedoro, "Correcting topographic effect on Landsat-8 images: an evaluation of using different DEMs in Indonesia," Proc.

SPIE 11311, Sixth Geoinformation Science Symposium, 113110L (21 November 2019); doi: 10.1117/12.2549109

SPIE Event: Sixth Geoinformation Science Symposium, 2019, Yogyakarta, Indonesia 


\title{
Correcting Topographic Effect on Landsat-8 Images: An Evaluation of Using Different DEMs in Indonesia
}

\author{
Deha Agus Umarhadia ${ }^{\text {ab }}$, Projo Danoedoro*a \\ ${ }^{a}$ Remote Sensing Laboratory, Department of Geographic Information Science, Faculty of \\ Geography, Universitas Gadjah Mada, Indonesia \\ ${ }^{\mathrm{b}}$ Graduate School of Environmental Science, Faculty of Environmental Earth Science, Hokkaido \\ University, Japan
}

\begin{abstract}
Topographic feature is one of the several factors affecting the distortion of the real reflectance value of objects. Digital processing used the surface reflectance values of satellite imagery needs the corrected images with the most minimized disturbances, hence several topographic correction methods using digital elevation data have been developed. This study examined the different result of topographic correction from several available elevation data in Indonesia, including SRTM DEM, topographic map (RBI), and DEMNAS. Sun-Canopy-Sensor $+\mathrm{C}(\mathrm{SCS}+\mathrm{C})$ correction using different DEMs was applied on Landsat-8 data over Menoreh Mountains, Indonesia. The results obtained showed that DEMNAS produced the most topographically normalized images based on statistical and visual analysis. The availability of DEMNAS throughout Indonesia is the advantage to be used as an input of this pre-processing method. However, it needs to be examined first since the quality is not surely similar to our study site.
\end{abstract}

Keywords: Topographic Correction, Image Pre-Processing, Landsat-8, DEM

\section{INTRODUCTION}

The reflectance value resulted from satellite sensor acquisition is affected by various variables including atmosphere, terrain elevation, slope, and aspect ${ }^{1}$. Remote sensing technique using passive system captures the reflectance of the objects on the earth surface from the energy of sunray. Therefore, objects facing on the sun directly have the higher value although the objects are similar to the others in other topography conditions. To reduce this disturbance in hilly and mountainous terrain, topographic correction is essential in order to obtain the surface reflectance accurately ${ }^{2}$.

Topographic correction can be applied on wavy and mountainous condition, and on all land cover types. Several researchers examined the topographic correction and focused on the method comparison in purpose to reduce topographic effects $2,4,5,6,7,8$. Most of them applied topographic correction on land cover classification ${ }^{9}$ and forest mapping ${ }^{10}$, whether it was multitemporal analysis or not.

There are two types of topographic correction methods consisting of band ratios and Digital Elevation Model (DEM) based correction ${ }^{11}$. Band ratios method is simpler, however, it could not be applied in multispectral classification since the result is a single band obtained from the two bands. DEM based correction involves elevation model in the processing which is used to calculate incident angle, the angle between normal angle and solar light ${ }^{12}$.

Adhikari et al examined the using of different DEM input in this pre-processing method and found that SRTM DEM is the most reducing terrain effect ${ }^{13}$. However, the availability of elevation data in Indonesia is different. This study aims to examine the different result of topographic correction from several available elevation data in Indonesia, including SRTM DEM, topographic map, and DEMNAS. DEMNAS, the newly available of elevation data in Indonesia provided by the Indonesian Geospatial Agency (BIG) is needed to be examined its performance in topographic correction. As the comparison, SRTM DEM which is widely used and produced a good result and contour-derived DEM from topographic map were used as well. 


\section{METHODS}

\subsection{Dataset}

Landsat-8 OLI imagery acquired on 22 February 2015 was used as the main data in this study. This image captures Menoreh Mountains located in the part of Special Region of Yogyakarta and Central Java Province. This imagery consists 9 multispectral bands and a panchromatic band. Cirrus correction, atmospheric correction, as well as geometric correction were applied before to be applied topographic correction.

There are three sources of DEM used as the input of pre-processing including SRTM DEM, topographic map, and DEMNAS. Shuttle Radar Topography Mission (SRTM) 1 arc-second was used as Digital Elevation Model (DEM). SRTM DEM provides widely digital elevation covered $60^{\circ}$ Northern to $56^{\circ}$ Southern Latitude acquired on 11-22 February 2000. The spatial resolution of this level is the same as $30 \mathrm{~m}$ of Landsat- 8 pixel size.

Derived from the 1:25.000 scale of Indonesian topographic map (RBI), the contour data with $12.5 \mathrm{~m}$ interval was converted to raster elevation data. To make it able to be an input, the pixel size was designed to $30 \mathrm{~m}$. DEMNAS is elevation data processed from various SAR data.

DEMNAS is elevation data generated from IFSAR ( $5 \mathrm{~m}$ spatial resolution), TERRASAR-X (5 m), and ALOS PALSAR $(11.25 \mathrm{~m})^{14}$. All the three inputs then are processed, assimilated with vertical datum correction, and gridded to $8.25 \mathrm{~m}$ resolution. This data covers the whole area of Indonesia provided by Geospatial Information Agency (BIG) Indonesia with free access.

\subsection{Topographic Correction}

By using DEM based correction, illumination or incident angle image should be processed first. The value of illumination depends on the relative orientation of pixel towards sun position ${ }^{1}$. It is obtained from the equation:

$$
\mathrm{IL}=\cos a \cos \theta_{z}+\sin a \sin \theta_{z} \cos \left(\phi_{a}-\phi_{o}\right)
$$

where IL is illumination; is $a$ slope angle; $\theta_{\mathrm{z}}$ is solar zenith angle; $\phi_{a}$ is solar azimuth angle; and $\phi_{\mathrm{o}}$ is aspect angle ${ }^{11}$.

As proven by Wu et al, Sun-Canopy-Sensor (SCS) is the best method in correcting slope and aspect condition ${ }^{6}$. This method projects the sloped surface to horizontal surface and preserves the geometry of canopy structure vertically ${ }^{15}$. SCS model is more appropriate than other methods because the sun-canopy geometry is vertically upright. Improving SCS model by adding $\mathrm{C}$ coefficient, Soenen et al modified it to become SCS $+\mathrm{C}$ which is expressed by:

$$
\rho_{H}=\rho_{T}\left(\frac{\cos a \cos \theta_{z}+c}{\mathrm{IL}+\mathrm{c}}\right)
$$

where $\rho_{\mathrm{T}}$ is the corrected surface reflectance and c parameter is the quotient between slope (b) and intercept (a) of the regression equation, versus IL obtained from samples ${ }^{16}$.

This study used vegetation as the samples because this object is available in various terrain condition in the study site, compared to the other objects. The total of 5,000 samples was used in the c calculation, and then these samples were also used in the validation analysis of the correction results.

\section{RESULTS AND DISCUSSION}

The evaluation of the topographic correction method was analyzed by comparing all the results visually and statistically. As seen in Figure 1, SCS + C topographic correction successfully reduced the terrain effect in the almost part of the study area using three sources of DEM. However, the topographic appearance could not be normalized well in the southeastern part of the Menoreh Mountains. By looking more detail in that area presented by Figure 2, the appearance of slope and aspect effect could happen because the geometric correction of Landsat- 8 imagery is not accurate enough in that area. Before correcting the topography, it is very essential to make the image is geometrically the same as the DEM, because a mis-registration error of one or two pixel causes error in retrieval surface reflectance especially in the gully and ridge areas ${ }^{17}$. This study used topographic map as the reference in geometric correction, however, the accuracy was lack due to the hilly terrain condition which needs more number and accurate reference points. 
Statistically, we tested the performance of each DEM by testing the standard deviation and the correlation value ${ }^{18}$. The declining of both standard deviation and correlation value indicates the reducing illumination effect on slopes ${ }^{18}$. We used the total of 5,000 samples of surface reflectance from each corrected image in the similar vegetation objects. The samples are the same as samples that we used in the empirical calculation of $\mathrm{c}$ parameter.

a.
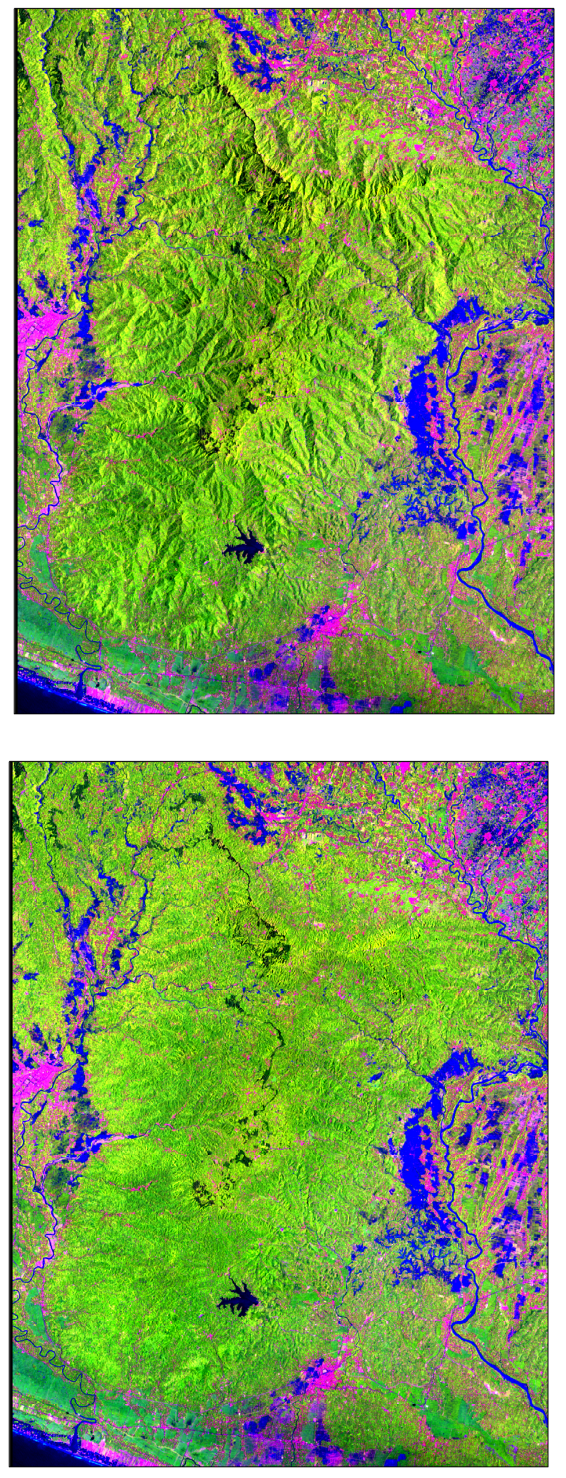

b.
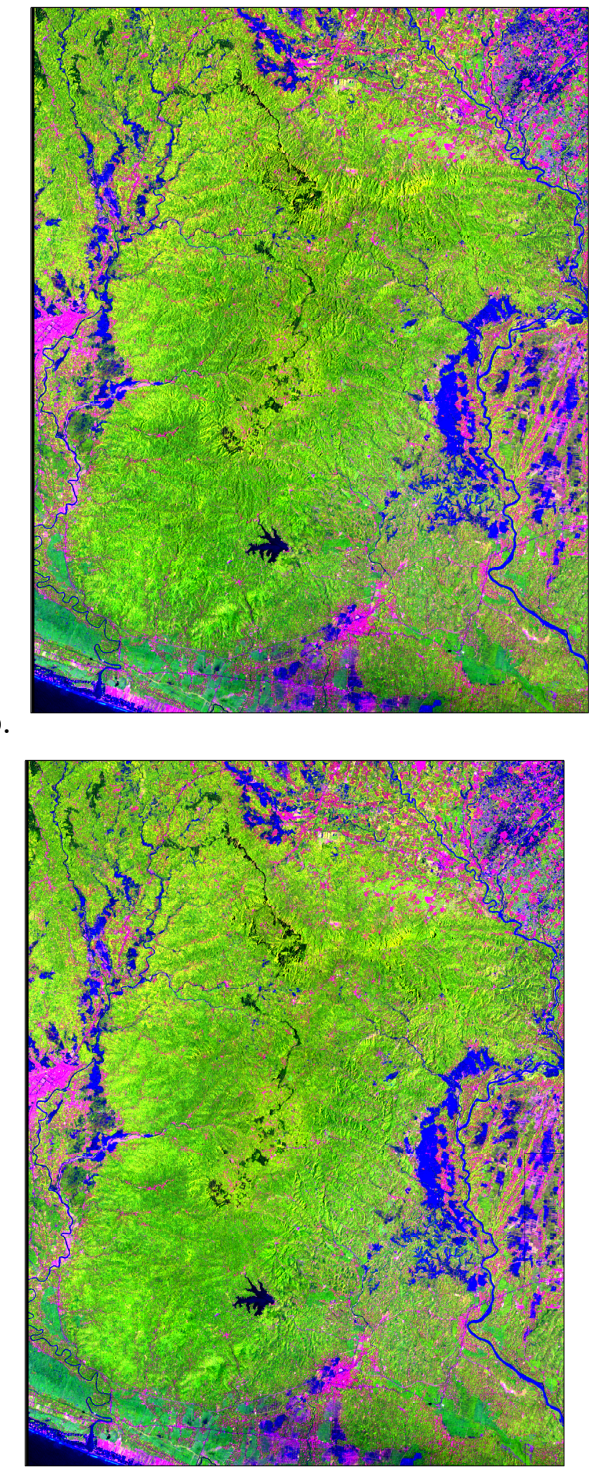

Figure 1. Landsat- 8 image of study area with 654 band composite before topographic correction (a), corrected using SRTM (b), RBI (c), and DEMNAS (d).

All methods have the decreasing value of standard deviation on each band of Landsat-8 image after it was corrected (Table 1). The declining value of standard deviation means the surface reflectance value of vegetation objects is getting more homogeneous. All standard deviations of each band are decreasing as it was corrected. Three of 30 meter Landsat- 8 bands including true color bands (Band 2 to 4 ) have the least variations on the vegetation pixel samples after being corrected using DEMNAS. Meanwhile, RBI derived DEM is the most successfully DEM reducing the standard deviation on Band 5 to 7 among the others. The difference value between DEMNAS and RBI is not really significant compared to the SRTM which is the least in declining the standard deviation, however, the values are also not too far different from other DEMs. 

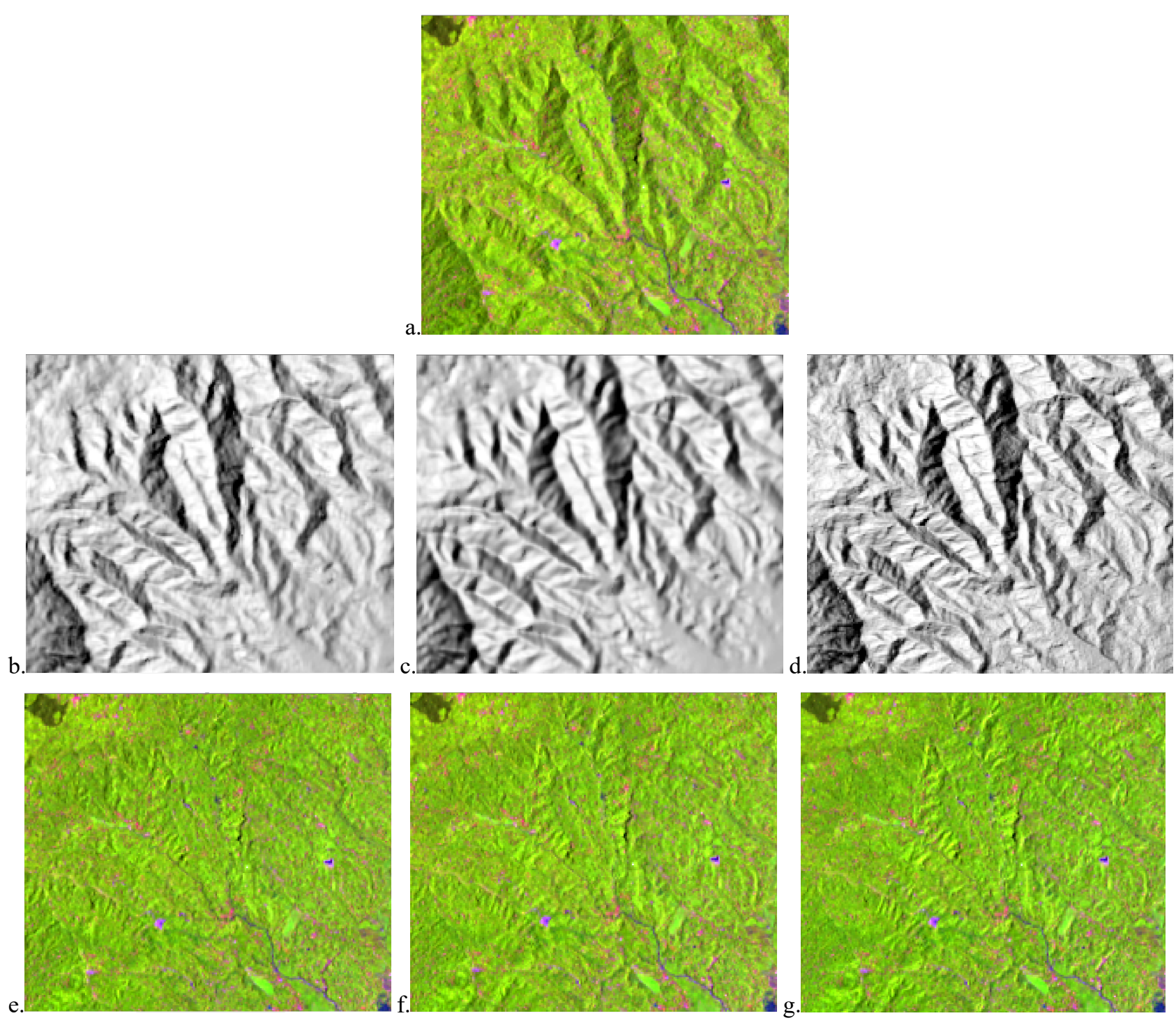

Figure 2. Uncorrected image (a), SRTM (b), RBI DEM (c), DEMNAS (d), and the result of topographic correction using SRTM (e), RBI DEM (f) and DEMNAS (g) respectively in the south-eastern part of Menoreh Mountains.

Table 1. Standard deviation of vegetation object samples.

\begin{tabular}{|c|c|c|c|c|c|c|}
\hline & \multicolumn{7}{|c|}{ Standard Deviation } \\
\cline { 2 - 7 } & Band 2 & Band 3 & Band 4 & Band 5 & Band 6 & Band 7 \\
\hline Original & 0.00231 & 0.00595 & 0.00354 & 0.06938 & 0.02836 & 0.01111 \\
\hline SRTM & 0.00190 & 0.00383 & 0.00248 & 0.03764 & 0.01563 & 0.00695 \\
\hline RBI & 0.00187 & 0.00365 & 0.00239 & 0.03447 & 0.01488 & 0.00673 \\
\hline DEMNAS & 0.00186 & 0.00364 & 0.00238 & 0.03483 & 0.01509 & 0.00682 \\
\hline
\end{tabular}

Correlation analysis between IL and surface reflectance can also be used to determine the success of topographic correction. As explained before, the higher sun ray exposing on the surface object, the higher value on the passive remote sensing image will be. Hence, IL and reflectance value is correlated well on the uncorrected images. It can be seen in Table 2, all bands have a strong relationship with IL from all DEMs indicated from the coefficients which are more than 0.5 . DEMNAS generated the highest correlation among other DEMs, followed by RBI. 
After being topographically corrected, all correlation coefficients are decreasing nearly zero. It means there is no effect of IL on the pixel value. By analyzing the lowest coefficient, two bands including Band 6 and Band 7 corrected by SRTM DEM have the lowest relationship, while the other bands are the result of correction using DEMNAS. Although producing the lowest relationship on the SWIR bands (Band 6 and 7), the decreasing of correlation values of SRTM are lower than the DEMNAS did. Figure 2 illustrated the declining correlation coefficient. We can see that all bands corrected using DEMNAS are located on the top above the other DEMs which means DEMNAS is the most successful elevation data to reduce the relationship between topography and pixel value. RBI

Table 2. Correlation coefficient between IL and surface reflectance of vegetation object samples.

\begin{tabular}{|c|c|c|c|c|c|c|c|}
\hline \multicolumn{2}{|c|}{} & \multicolumn{7}{|c|}{ Correlation Coefficient } \\
\cline { 3 - 8 } \multicolumn{2}{c|}{} & Band 2 & Band 3 & Band 4 & Band 5 & Band 6 & Band 7 \\
\hline \multirow{3}{*}{ SRTM } & Original & 0.54171 & 0.72035 & 0.67979 & 0.82009 & 0.79643 & 0.72019 \\
\cline { 2 - 8 } & SCS+C & 0.03984 & 0.04585 & 0.04723 & 0.04404 & 0.03205 & 0.00534 \\
\hline \multirow{2}{*}{ RBI } & Original & 0.57491 & 0.75431 & 0.71332 & 0.84482 & 0.81363 & 0.73579 \\
\cline { 2 - 8 } & SCS+C & 0.03954 & 0.05155 & 0.04840 & 0.04981 & 0.03865 & 0.01539 \\
\hline \multirow{2}{*}{ DEMNAS } & Original & 0.57712 & 0.76549 & 0.72446 & 0.84964 & 0.82082 & 0.74590 \\
\cline { 2 - 8 } & SCS+C & 0.03281 & 0.04487 & 0.04302 & 0.04318 & 0.03436 & 0.01581 \\
\hline
\end{tabular}

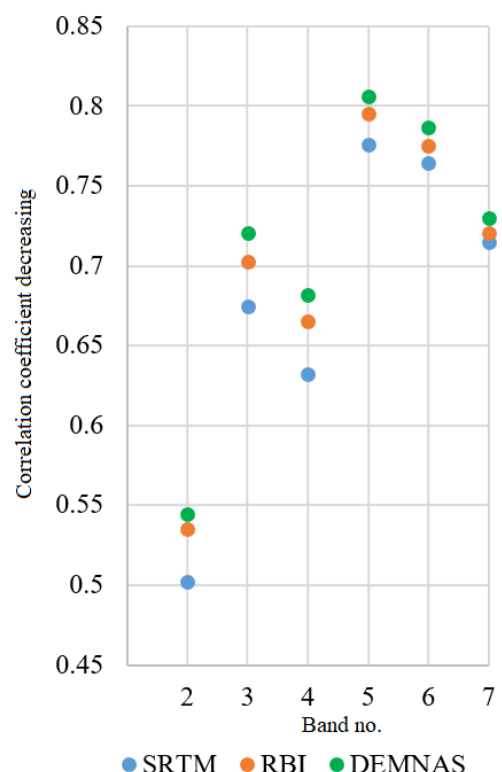

Figure 3. Decreasing of correlation coefficient between IL and surface reflectance of vegetation object samples.

Based on the reduction in standard deviation value and correlation coefficient, DEMNAS is considered as the most efficient DEM to correct the topographic feature. The altitude values of this data represent the elevation of surface object instead of terrain or ground elevation, since DEMNAS is the product of SAR data which cannot penetrating to the ground, hence it is called Digital Surface Model (DSM). It is different from RBI that the DEM was derived from contour representing the ground elevation. The use of DSM from DEMNAS is more appropriate in the application of topographic correction because the surface condition is similar to DSM instead of ground condition. Moreover, its original spatial resolution, 8.25 meter is qualified the recommendation mentioned by Hantson and Chuvieco ${ }^{4}$. They suggested the use of elevation data which has pixel size finer than $1 / 3$ of spatial resolution of image to be corrected ${ }^{4}$. SRTM is DSM as well, however, it was resampled from the original 90 meter DEM although with additional field measurement data.

Being available for all areas in Indonesia, DEMNAS becomes the first ready-to-use DSM in this country. It performed well to be the input of topographic correction in the study area. However, the quality of this elevation data might be 
different in the other areas in Indonesia due to the different sources used. Further study about the performance of this DSM in other applications and areas as well is essential to be assessed.

\section{CONCLUSION}

We evaluated the performance of three sources of DEM in correcting topographic feature on Landsat-8 image. Based on statistical analysis including standard deviation and correlation, as well as visual analysis. DEMNAS performed the most significant in reducing the slope and aspect effect. RBI based DEM followed DEMNAS in the second place, while SRTM is the least significant. However, all DEMs could normalize the terrain condition massively. The geometric condition between imagery and elevation data should be paid the attention, since small difference location could affect the results, especially in hilly mountains. Hence, geometric correction with high accuracy is essential prior to the further pre-processing method. The availability of DEMNAS in Indonesia becomes an advantage to be used as an input of this image correction. The quality of DEMNAS in other regions may be different, hence it needs to be examined first before being used.

\section{REFERENCES}

[1] Jensen, J. R., [Introductory Digital Image Processing - A Remote Sensing Perspective], $3^{\text {rd }}$ ed., Englewood Cliff, N.J. Pearson Prentice Hall (2005).

[2] Yanzhen, W., Zoucheng, W., Fupin, Y., and Luo, X. B., "Research of Improved Minnaert Topographic Correction Model and Application," Applied Mechanics and Materials, 543-547 (2014).

[3] Richter, R., Kellenbeger, T., and Kaufmann, H., "Comparison of Topographic Correction Methods," Remote Sensing 1, 184-196 (2009).

[4] Hantson, S., and Chuvieco, E., "Evaluation of Different Topographic Correction Methods for Landsat Imagery," International Journal of Applied Earth Oservation and Geoinformation 13, 691-700 (2011).

[5] Sola, I., González-Audícana, M., and Álvarez-Mozos, J., "Multi-criteria evaluation of topographic correction methods," Remote Sensing of Environment 184, 247-262 (2016).

[6] Wu, Q., Jin, Y., and Fan, H., "Evaluating and comparing performances of topographic correction methods based on multi-source DEMs and Landsat-8 OLI data," International Journal of Remote Sensing, 37(19), 4712-4730, DOI:10.1080/01431161.2016.1222101 (2016).

[7] Zhou, Y., Jiang, H., Wang, Z., Yang, X., and Geng, E., "Assessment of Four Typical Topographic Corrections in Landsat TM Data for Snow Cover Areas,” XXIII ISPRS Congress, 12-19 July 2016, Prague, Czech Republic (2016).

[8] Zhang, Z., He, G., Zhang, X., Long, T., Wang, G., and Wang, M., "A coupled atmospheric and topographic correction algorithm for remotely sensed satellite imagery over mountainous terrain," GIScience \& Remote Sensing, DOI:10.1080/15481603.2017.1382066 (2017).

[9] Vanonckelen, S., Lhermitte, S., and Rompaey, A. V., "The Effect of Atmospheric and Topographic Correction Methods on Land Cover Classification Accuracy," International Journal of Applied Earth Observation and Geoinformation 24, 9-21 (2013).

[10]Wei, C., Qingjiu, T., and Liming, W., "A Model of Topographic Correction and Reflectance Retrieval for Optical Satellite Data in Forested Areas," The International Archives of the Photogrammetry, Remote Sensing and Spatial Information Sciences, XXXVII, Part B6b, Beijing (2008).

[11]Riano, D., Chuvieco, E., Salas, J., and Aguado, I., "Assessment of Different Topographic Corrections in Landsat-TM Data for Mapping Vegetation Types," IEEE Transactions on Geoscience and Remote Sensing, 41(5), May (2003).

[12] Teillet, P. M., Guindon, B., and Goodenough, D. G., "On the Slope-Aspect Correction of Multispectral Scanner Data," Canadian Journal of Remote Sensing: Vol.8 No.2, 84-106, DOI: 10.1080/07038992.1982.10855028 (1982).

[13] Adhikari, H., Heiskanen, J., Maeda, E. E., and Pellikka, P. K. E., "Does Topographic Normalization of Landsat Images Improve Fractional Tree Cover Mapping in Tropical Mountain?," The International Archives of the Photogrammetry, Remote Sensing and Spatial Information Sciences, Volume XL-7/W3, 2015 36th International Symposium on Remote Sensing of Environment, 11-15 May 2015, Berlin, Germany (2015).

[14] Geospatial Information Agency, "DEMNAS", BIG, 2018, <http://tides.big.go.id/DEMNAS> (21 June 2019). 
[15] Gu, D., and Gillespie, A., "Topographic normalization of Landsat TM images of forest based on subpixel suncanopy-sensor geometry," Remote Sens. Environ., 64, 166-175 (1998).

[16] Soenen, S. A., Peddle, D. R., and Coburn, C. A., "SCS+C: A Modified Sun-Canopy-Sensor Topographic Correction in Forested Terrain," IEEE Transactions on Geoscience and Remote Sensing, 43(9) September (2005).

[17]Li, F., Jupp, D. L. B., and Thankappana, M., "Using High Resolution DSM Data to Correct The Terrain Illumination Effect in Landsat Data," 19th International Congress on Modelling and Simulation, Perth, Australia, 12-16 December (2011).

[18] Gao, M. L., Zhao, W. J., Gong, Z. N., Gong, H. L., Chen, Z., and Tang, X. M., "Topographic Correction of ZY3 Satellite Images and Its Effects on Estimation of Shrub Leaf Biomass in Mountainous Areas," Remote Sens. 6, 2745-2764; doi:10.3390/rs6042745 (2014). 